\title{
Quality of farmer's life in rural areas in Vietnam
}

\author{
Thi Mai Lan Nguyen ${ }^{1, *}$, Thu Trang Vu ${ }^{1}$, Nhan Ai Nguyen $^{1}$, Thi Thanh Nga Nguyen ${ }^{1}$, Thi \\ Xuan Tran ${ }^{1}$, Thuy Hao $\mathrm{Ngo}^{2}$, Thi Hoa Mai Nguyen ${ }^{3}$, Thi Nhung Nong ${ }^{1}$, and Thu Trang \\ Hoang ${ }^{1}$ \\ ${ }^{1}$ Graduate Academy of Social Sciences, 477 Nguyen Trai, Thanh Xuan, Hanoi, 10000, Vietnam \\ ${ }^{2}$ Xiamen University, 442 Siming South Road, Xiamen, Fujian, 361005, China \\ ${ }^{3}$ Institute of Human Studies, 9A Kim Ma Thuong, Ba Dinh, Hanoi, 10000, Vietnam
}

\begin{abstract}
Improving quality of life (QOL) is an important objective. This study measured the QOL of farmers in rural areas in Vietnam using the WHOQOL-BREF. 600 farmers from 5 provinces in Vietnam participated in the study. Farmers reported low QOL, with psychological dimension had the highest QOL score and environmental dimension had lowest QOL. Male, young, well-educated, married, healthy farmers and farmers who had average living standard, living in small families, living with having less than 3 working members, and have savings were more likely to have higher QOL. However, only 3 factors predicted QOL: education, living standard and number of working members. Implications on Vietnamese family culture and the role of agriculture in modern society were discussed.
\end{abstract}

\section{Introduction}

Quality of life (QOL) is a global goal of development. Since 2015, 193 countries and territories have joined the United Nations in achieving the Sustainable Development Goals, with the aim to improve the planet and the quality of human life around the world by the year 2030 [1]. QOL is also a major concern of individuals and communities [2]. The quality of life, therefore has been a frequently discussed issue in various disciplines, including philosophy, medicine, anthropology, culture, psychology, economics, etc. with a great number of published works [3].

QOL is a particularly difficult concept to be measured because it has many definitions, and can be measured on a variety of scales, ranging from an individual to a community or a country [4]. Costanza et al. (2007) described QOL as "a multidimensional concept, containing both objective and subjective elements, which interact with each other" [5]. The objective dimension of QOL includes observable indicators such as income, living standards, access to healthcare and social services, family life and social life; while the subjective dimension includes perception of work, family, social life, entertainment, and health [6]. Over time, the attention on QOL has shifted from the utilitarian approach with a heavy focus on wealth and income, to a combination of monetary and non-monetary dimensions in the mid-seventies, to subjective measures in modern literature $[7,8]$. In line

*Corresponding author: mailantamly@gmail.com 
with the modern approach to QOL, in this article, we used the definition of QOL proposed by the World Health Organization: "Quality of life is defined as individuals' perceptions of their position in life in the context of the culture and value systems in which they live and in relation to their goals, expectations, standards and concerns" [9, p.43].

In social and political settings, the urban-rural comparison of QOL is frequently mentioned among the academia and thus attracted attention of policy makers. While researchers agree that there exists a gap in QOL between urban and rural residents, the direction of the discrepancy varies across locations. QOL of rural people is higher than urban people in America [10]; yet the opposite is found in Asia [11]. Nevertheless, rural QOL has been the frequent target of support of all governments, ranging from Rural Prosperity program by the United States Department of Agriculture to the program on Improving Quality of Life of farmers and fishers by the Korean government.

Rural QOL and rural well-being are closely linked to agriculture through social, economic and environmental indicators [12]. Agriculture is the main livelihood of people in rural areas. Agriculture contributes to improving the rural QOL through multifunctional activities, including environmental functions, and food security, etc. [13]. Therefore, in order to enhance the QOL in rural areas, it is necessary to carry out regional and national agricultural development strategies. Measures to be taken include improving infrastructure to support rural identity, motivating and engaging residents, as well as supporting cultural, social and sporting activities of the people in the agricultural areas [14].

In Vietnam, $65.6 \%$ of the population live in the rural areas [15]. While there have been attempts to measure QOL in rural areas in Vietnam, most studies use objective indicators to assess QOL and identify its predictors. Subjective QOL has been considered in recent research, yet the focus is directed towards health-related QOL of people with illness. Few studies has been conducted on healthy populations using international tools. This paper aims to study the QOL of farmers in rural areas in Vietnam. We use WHO's definition and measurement of QOL to evaluate the perception of life aspects of farmers in rural areas in Vietnam. We also examined factors predicting QOL of farmers in rural areas in order to discuss policy implications.

\section{Methods}

\subsection{Sample}

The study was conducted at 5 provinces in 3 regions of Vietnam: Thai Binh, Tuyen Quang, Ha Tinh, Ben Tre and Ba Vi. Of the 5 locations, 3 are in the north of Vietnam, 1 in the central region and 1 in the south. The locations were selected to represent different terrains affecting modes of agriculture. Tuyen Quang and Ha Tinh are provinces in the mountainous area; its residents face many difficulties in agriculture and travelling. Thai Binh and Ben Tre are provinces in the delta area; farming is easier and is the main method of production. $\mathrm{Ba} \mathrm{Vi}$ is the outskirt of Hanoi, representing the near-urban setting.

Rural areas were determined by administrative units. In Vietnam, every province has provincial cities representing the urban areas and communes representing the rural areas. We randomly selected 1 commune per chosen province. Surveys were sent to 120 random farmers in each commune with the support of local authorities. In total, 600 farmers participated in this study, response rate $100 \%$.

\subsection{Measures}


Quality of life was measured by WHOQOL-BREF, an abbreviated version of the Quality of Life Scale designed by the World Health Organization (WHO, 1996). The WHOQOLBREF includes 26 items measuring general quality of life, general health and 4 domains of quality of life: (i) physical health, (ii) psychological health, (iii) social relationships, and (iv) environment. The scale was translated into Vietnamese using back-to-back translation.

Demographic information included gender, age, education (primary school, secondary school, high school), marital status, living standard (below average, average, above average), number of family members living in the same household, number of working family members, and income-expense balance (income $>$ expense or income $<$ expense).

Data in this study were taken from the dataset collected in the Ministry-funded project: The relationship between the state, community and family in Vietnam, conducted in 20172018. The current questionnaire comprised $1 / 3$ of the complete survey.

Data analysis was conducted using SPSS 20.0. Besides descriptive statistics, logistic regression and linear regression were performed. A significant level of $\mathrm{p}<0.05$ was used.

\section{Results}

\subsection{Characteristics of the study populations}

The participant characteristics were presented in Table 1.

Table 1. Descriptive characteristics of studied population.

\begin{tabular}{|c|c|c|}
\hline & $\mathbf{N}$ & $\%$ \\
\hline \multicolumn{3}{|c|}{ Age: Mean $=51.98, \mathrm{SD}=10.88$} \\
\hline \multicolumn{3}{|c|}{\begin{tabular}{l|l} 
Gender &
\end{tabular}} \\
\hline Male & 305 & 50.8 \\
\hline Female & 295 & 49.2 \\
\hline \multicolumn{3}{|l|}{ Marital status } \\
\hline Single & 137 & 22.8 \\
\hline Married & 463 & 77.2 \\
\hline \multicolumn{3}{|l|}{ Health status } \\
\hline Sick & 53 & 8.8 \\
\hline Normal & 547 & 91.2 \\
\hline \multicolumn{3}{|l|}{ No. of family members } \\
\hline$\leq 4$ & 367 & 61.2 \\
\hline$>4$ & 233 & 38.8 \\
\hline \multicolumn{3}{|l|}{ Living standard } \\
\hline Above average & 63 & 10.5 \\
\hline Average & 261 & 43.5 \\
\hline Below average & 276 & 46.0 \\
\hline \multicolumn{3}{|l|}{ Education } \\
\hline Illiterate & 175 & 29.2 \\
\hline Primary school & 141 & 23.5 \\
\hline Secondary school & 149 & 24.8 \\
\hline High school & 135 & 22.5 \\
\hline \multicolumn{3}{|l|}{ Income-expense balance } \\
\hline Income $>$ Expense & 317 & 52.8 \\
\hline Income $<$ Expense & 283 & 47.2 \\
\hline \multicolumn{3}{|c|}{ No. of working members in the family } \\
\hline$\leq 3$ & 349 & 58.2 \\
\hline$>3$ & 251 & 41.8 \\
\hline
\end{tabular}


The sample was equally distributed in term of gender and education. While the age range of the sample varies from under 30 to 70 , the mean age was 51.98 years old, implying an aging population. The sample was skewed towards farmers who were married $(77.2 \%)$, healthy $(91.2 \%)$, having average $(43.5 \%)$ or below-average $(46.0 \%)$ standard of living, living in nuclear families $(61.2 \%)$. Only a minority $(10 \%)$ of farmers had above-average living standard. Given the sample was chosen using random selection, its skewness reflects the living standard of farmers in rural areas in Vietnam. The majority of farmers in rural area are married, economically disadvantaged, living in nuclear families and are in healthy condition.

\subsection{Quality of life profile and its associated factors among farmers in rural areas in Vietnam}

Table 2 presents the WHOQOL-BREF overall and domain scores. The overall QOL of farmers in rural area in Vietnam was poor: $\mathrm{M}=2.623, \mathrm{SD}=0.642$; while their satisfaction with health was slightly above average: $\mathrm{M}=3.412, \mathrm{SD}=0.608$. Given that the majority of the population was in normal health, the general health score reflected subjective perception of farmers of their health status.

No huge difference between domain scores were observed. Across domains of QOL, the psychological domain had the highest score of satisfaction $(\mathrm{M}=12.469, \mathrm{SD}=1.226)$, while the environment domain had the lowest score $(\mathrm{M}=11.930, \mathrm{SD}=1.348)$.

Table 2. QOL scores of farmers in rural areas in Vietnam.

\begin{tabular}{|c|c|c|c|c|c|c|}
\hline & \multicolumn{6}{|c|}{ QOL scores } \\
\hline & $\begin{array}{c}\text { Overall } \\
\text { QOL }\end{array}$ & $\begin{array}{c}\text { General } \\
\text { health }\end{array}$ & $\begin{array}{c}\text { Physical } \\
\text { health } \\
\text { domain }\end{array}$ & $\begin{array}{c}\text { Psychological } \\
\text { domain }\end{array}$ & $\begin{array}{c}\text { Social } \\
\text { relationship } \\
\text { domain }\end{array}$ & $\begin{array}{c}\text { Environment } \\
\text { domain }\end{array}$ \\
\hline M & 2.623 & 3.412 & 12.031 & 12.467 & 11.631 & 11.930 \\
\hline SD & 0.642 & 0.608 & 1.459 & 1.226 & 2.186 & 1.347 \\
\hline
\end{tabular}

The mean score of each domain across socio-economic characteristics were presented in Table 3. Almost all socio-economic characteristics created significant differences in QOL overall score, domain scores and general health score.

Male, young and highly educated farmers had higher QOL general score and domain scores, as well as higher general health score. Married farmers and farmers with family of less than 4 members had higher QOL and general health than single farmers and those with big families. It is interesting to note that farmers with better health status are not more satisfied with their health than those who were sick, even though they had higher QOL in general item and in 3 out of 4 domains.

Farmers with average living standard had higher overall QOL and domain scores than those better-off or worse-off. People with less than 3 working members in the family also had higher QOL and satisfaction with their health.

Table 3. QOL score by domains compared across socio-economic characteristics $\left({ }^{*} \mathrm{p}<0.05\right.$; $* * \mathrm{p}<0.01)$.

\begin{tabular}{|l|c|c|c|c|c|c|}
\hline & \multicolumn{6}{|c|}{ QOL mean score } \\
\hline & $\begin{array}{c}\text { Overall } \\
\text { QOL }\end{array}$ & $\begin{array}{c}\text { General } \\
\text { health }\end{array}$ & $\begin{array}{c}\text { Physical } \\
\text { health } \\
\text { domain }\end{array}$ & $\begin{array}{c}\text { Psychological } \\
\text { domain }\end{array}$ & $\begin{array}{c}\text { Social } \\
\text { relationship } \\
\text { domain }\end{array}$ & $\begin{array}{c}\text { Environment } \\
\text { domain }\end{array}$ \\
\hline
\end{tabular}




\begin{tabular}{|c|c|c|c|c|c|c|}
\hline \multicolumn{7}{|l|}{ Gender } \\
\hline Male & 2.898 & 3.711 & 12.665 & 12.8415 & 12.524 & 12.5016 \\
\hline Female & 2.339 & 3.101 & 11.376 & 12.0836 & 10.707 & 11.3390 \\
\hline $\mathrm{t}$ & $11.831 * *$ & $14.199 * *$ & $12.049 * *$ & $7.951 * *$ & $11.185^{* *}$ & $11.701 * *$ \\
\hline \multicolumn{7}{|l|}{ Age } \\
\hline Under 45 & 2.718 & 3.544 & 12.247 & 12.551 & 12.015 & 12.169 \\
\hline Over 45 & 2.583 & 3.355 & 11.939 & 12.433 & 11.467 & 11.827 \\
\hline $\mathrm{t}$ & $2.340^{*}$ & $3.536^{* *}$ & $2.385^{*}$ & 1.085 & $2.831^{* *}$ & $2.866^{* *}$ \\
\hline \multicolumn{7}{|c|}{ Marital status } \\
\hline Single & 2.533 & 3.333 & 11.844 & 12.389 & 11.364 & 11.783 \\
\hline Married & 2.927 & 3.679 & 12.663 & 12.740 & 12.535 & 12.427 \\
\hline $\mathrm{t}$ & $-7.068 * *$ & $-6.027 * *$ & $-5.932 * *$ & $-3.150^{*}$ & $-5.738 * *$ & $-5.011 * *$ \\
\hline \multicolumn{7}{|c|}{ Health status } \\
\hline Sick & 2.453 & 3.321 & 11.472 & 12.428 & 10.969 & 11.481 \\
\hline Normal & 2.640 & 3.420 & 12.086 & 12.473 & 11.695 & 11.973 \\
\hline $\mathrm{t}$ & $-2.030^{*}$ & -1.331 & $-2.944^{*}$ & -0.256 & $-2.319^{*}$ & $-2.868 * *$ \\
\hline \multicolumn{7}{|c|}{ No. of family members } \\
\hline$\leq 4$ & 2.727 & 3.482 & 12.310 & 12.663 & 11.978 & 12.168 \\
\hline$>4$ & 2.459 & 3.300 & 11.592 & 12.163 & 11.084 & 11.553 \\
\hline $\mathrm{t}$ & $5.092 * *$ & $3.732 * *$ & $6.066^{* *}$ & $4.961 * *$ & $4.977 * *$ & $5.586^{* *}$ \\
\hline \multicolumn{7}{|c|}{ Living standard } \\
\hline Average & 2.698 & 3.460 & 12.136 & 12.603 & 11.640 & 11.921 \\
\hline $\begin{array}{l}\text { Above } \\
\text { average }\end{array}$ & 3.107 & 3.865 & 13.189 & 13.154 & 13.364 & 13.027 \\
\hline $\begin{array}{l}\text { Below } \\
\text { average }\end{array}$ & 2.149 & 2.971 & 10.913 & 11.790 & 9.990 & 10.895 \\
\hline $\mathrm{F}$ & $351.407 * *$ & $308.487 * *$ & $421.968 * *$ & $117.552 * *$ & $399.210 * *$ & $421.718^{* *}$ \\
\hline \multicolumn{7}{|l|}{ Education } \\
\hline Illiterate & 2.394 & 3.183 & 11.415 & 12.183 & 10.697 & 11.317 \\
\hline $\begin{array}{c}\text { Primary } \\
\text { school }\end{array}$ & 2.574 & 3.376 & 11.850 & 12.416 & 11.508 & 11.865 \\
\hline $\begin{array}{l}\text { Secondary } \\
\text { school }\end{array}$ & 2.738 & 3.544 & 12.395 & 12.676 & 12.268 & 12.191 \\
\hline $\begin{array}{l}\text { High } \\
\text { school }\end{array}$ & 2.844 & 3.600 & 12.618 & 12.667 & 12.267 & 12.504 \\
\hline $\mathrm{F}$ & $15.624 * *$ & $17.178^{* *}$ & $23.947 * *$ & $5.987 *$ & $21.275^{* *}$ & $28.239^{* *}$ \\
\hline \multicolumn{7}{|c|}{ No. of working family members } \\
\hline$\leq 3$ & 2.968 & 3.739 & 12.894 & 13.037 & 12.863 & 12.726 \\
\hline$>3$ & 2.143 & 2.956 & 10.832 & 11.679 & 9.918 & 10.823 \\
\hline $\mathrm{t}$ & $20.074 * *$ & $22.490^{* *}$ & $24.478^{* *}$ & $15.975 * *$ & $22.874^{* *}$ & $25.311^{* *}$ \\
\hline \multicolumn{7}{|c|}{ Income-expense balance } \\
\hline $\begin{array}{l}\text { Income }< \\
\text { Expense }\end{array}$ & 2.505 & 3.289 & 11.729 & 12.344 & 11.119 & 11.647 \\
\hline $\begin{array}{l}\text { Income }> \\
\text { Expense }\end{array}$ & 2.729 & 3.520 & 12.301 & 12.580 & 12.088 & 12.183 \\
\hline $\mathrm{t}$ & $-4.301 * *$ & $-4.755^{* *}$ & $-4.881 * *$ & $-2.367 *$ & $-5.556^{* *}$ & $-4.980 * *$ \\
\hline
\end{tabular}

\subsection{Predictors of quality of life of farmers in rural areas in Vietnam}

To analyze factors predicting QOL of farmers in rural areas in Vietnam, we ran two separate analyses: logistic regression for overall QOL score (Table 4) and linear regression for QOL domain scores (Table 5). 
Out of 9 predictors, 3 factors had significant effect on overall QOL. Farmers who had finished secondary school were more likely to have higher overall QOL than illiterate farers: OR=4.826 (95\% CI: 1.517-15.348). Living standard was also a significant predictor of overall QOL: farmers with above-average living standard had higher QOL than those with average living standard $(\mathrm{OR}=58.130$ [95\% CI: 7.006-482.325]) and farmers with below-average living standard had lower QOL than those with average living standard $(\mathrm{OR}=0.117$ [95\% CI: 0.052-0.256]). Families with more than 3 employed members had lower overall QOL: OR=0.139 (95\% CI: 0.058-0.335).

Table 4. Logistic regression for predictors of overall QOL score.

\begin{tabular}{|c|c|c|c|}
\hline \multirow{2}{*}{ Characteristics } & \multicolumn{2}{|c|}{ Unadjusted analysis } & \multirow[b]{2}{*}{$\mathbf{p}$} \\
\hline & OR & $95 \% \mathrm{CI}$ & \\
\hline \multicolumn{4}{|l|}{ Gender (ref: Male) } \\
\hline Female & 0.600 & $(0.265-1.357)$ & 0.220 \\
\hline \multicolumn{4}{|l|}{ Age (ref: $\leq 45$ yo) } \\
\hline Above 45 yo & 2.649 & $(0.779-9.014)$ & 0.119 \\
\hline \multicolumn{4}{|c|}{ Education (ref: Illiterate) } \\
\hline Primary school & 1.584 & $(0.582-4.306)$ & 0.368 \\
\hline Secondary school & 4.826 & $(1.517-15.348)$ & 0.008 \\
\hline High school & 3.852 & $(0.773-19.206)$ & 0.100 \\
\hline \multicolumn{4}{|c|}{ Marital status (ref: Single) } \\
\hline Married & 0.197 & $(0.071-0.545)$ & 0.002 \\
\hline \multicolumn{4}{|c|}{ Health status (ref: Sick) } \\
\hline Normal & 0.826 & $(0.231-2.955)$ & 0.769 \\
\hline \multicolumn{4}{|c|}{ Living standard (ref: Above average) } \\
\hline Average & 58.130 & $(7.006-482.325)$ & 0.000 \\
\hline Below average & 0.117 & $(0.052-0.265)$ & 0.000 \\
\hline \multicolumn{4}{|c|}{ No. of family members (ref: $\leq 4$ ) } \\
\hline$>4$ people & 1.450 & $(0.627-3.356)$ & 0.385 \\
\hline \multicolumn{4}{|c|}{ No. of working family members (ref: $\leq 3)$} \\
\hline$>3$ people & 0.139 & $(0.058-0.335)$ & 0.000 \\
\hline \multicolumn{4}{|c|}{ Income-expense balance (ref: Income > Expense) } \\
\hline Income $<$ Expense & 1.199 & $(0.553-2.599)$ & 0.645 \\
\hline
\end{tabular}

Education, living standard and number of employed family members showed stable patterns of influence on the 4 domains of QOL (see Table 5). Physical health was predicted by education, as both secondary and high school education can improve satisfaction with physical health: $\beta=0.109$ and 0.118 , respectively; living standard: above-average living standard increased satisfaction with physical health $(\beta=0.207)$ while below-average reduced it $(\beta=-0.263)$; number of employed family members: $\beta=-0.285$; and age: $\beta=0.191$. Psychological domain was negatively predicted by below-average living standard: $\beta=-0.187$ and the number of employed family members: $\beta=-0.351$. Social relationship domain was predicted by secondary school education: $\beta=0.097$; living standard: above-average living standard increased satisfaction with social relationship $(\beta=0.279)$ while below-average reduced it $(\beta=-0.259)$; and number of employed family members: $\beta=-0.240$. Environment domain was predicted by high school education: $\beta=0.103$; living standard: above-average living standard increased satisfaction with social relationship $(\beta=0.273)$ while belowaverage reduced it $(\beta=-0.251)$; and number of employed family members: $\beta=-0.272$.

Table 5. Linear regression for predictors of QOL domains.

\begin{tabular}{|c|c|c|c|c|}
\hline Characteristics & $\begin{array}{c}\text { Physical health } \\
\text { domain }\end{array}$ & $\begin{array}{c}\text { Psychological } \\
\text { domain }\end{array}$ & $\begin{array}{c}\text { Social } \\
\text { relationship } \\
\text { domain }\end{array}$ & $\begin{array}{c}\text { Environment } \\
\text { domain }\end{array}$ \\
\hline
\end{tabular}




\begin{tabular}{|c|c|c|c|c|c|c|c|c|}
\hline & 及 & p & 及 & p & 及 & p & B & $\mathbf{p}$ \\
\hline Gender (Female) & -.046 & .165 & -.022 & .615 & -.012 & .735 & -.025 & .445 \\
\hline $\begin{array}{c}\text { Age (Above } 45 \\
\text { yo) }\end{array}$ & .091 & .013 & .007 & .886 & -.002 & .954 & .040 & .272 \\
\hline \multicolumn{9}{|c|}{ Education (ref: Illiterate) } \\
\hline Primary school & .006 & .862 & -.023 & .580 & .037 & .275 & .048 & .141 \\
\hline Secondary school & .109 & .004 & .005 & .913 & .097 & .015 & .074 & .051 \\
\hline High school & .118 & .007 & -.050 & .371 & .016 & .726 & .103 & .018 \\
\hline $\begin{array}{l}\text { Marital status } \\
\text { (Married) }\end{array}$ & -.045 & .131 & .054 & .158 & -.029 & .354 & -.002 & .958 \\
\hline $\begin{array}{l}\text { Health status } \\
\text { (Normal) }\end{array}$ & .026 & .356 & -.058 & .112 & -.004 & .886 & .000 & .994 \\
\hline \multicolumn{9}{|c|}{ Living standard (ref: Above average) } \\
\hline Average & .207 & .000 & .094 & .138 & 279 & .000 & .273 & .000 \\
\hline Below average & -.263 & .000 & -.187 & .003 & -.259 & .000 & -.251 & .000 \\
\hline $\begin{array}{l}\text { No. of family } \\
\text { members }(>4)\end{array}$ & .004 & .899 & -.028 & .457 & .032 & .300 & .016 & .592 \\
\hline $\begin{array}{l}\text { No. of labor in } \\
\text { family }(>3)\end{array}$ & -.285 & .000 & -.351 & .000 & -.240 & .000 & -.272 & .000 \\
\hline $\begin{array}{l}\text { Income-expense } \\
\text { balance (Income } \\
\quad<\text { Expense) }\end{array}$ & .006 & .834 & .016 & .666 & -.043 & .142 & -.004 & .881 \\
\hline$p_{\text {model }}$ & \multicolumn{2}{|c|}{$<0.001$} & \multicolumn{2}{|c|}{$<0.001$} & \multicolumn{2}{|c|}{$<0.001$} & \multicolumn{2}{|c|}{$<0.001$} \\
\hline $\mathrm{R}^{2}$ & \multicolumn{2}{|c|}{0.585} & \multicolumn{2}{|c|}{0.320} & \multicolumn{2}{|c|}{0.556} & \multicolumn{2}{|c|}{0.589} \\
\hline
\end{tabular}

It should be noted that while QOL of farmers was predicted by 3 factors: education, living standard and number of employed family members, general health was only predicted by gender, with female farmers had higher general health than male farmers: $\mathrm{OR}=0.273$ (95\% CI: 0.109-0.686). Other factors did not have significant impact on farmers' satisfaction with heath. In each domain, the three variables were able to explain $32 \%$ to $58.9 \%$ of the variance in domain score.

\section{Discussion}

In this paper, we aimed to assess the quality of life of farmers in rural areas in Vietnam through an internationally accepted measure - the WHOQOL-BREF. Our study contributed to the existing bodies of research on rural QOL. Given that research on farmers' QOL in Vietnam remain limited in number, this study provides a good basis for comparison with international studies, especially when the WHOQOL is increasingly being used by international organizations and researchers as a global indicator of subjective QOL. Moreover, evidence from this study can yield useful insight into farmers' QOL in an agricultural-based developing country like Vietnam. This study and future studies on QOL of farmers in rural areas are a good start for developing appropriate policies and program to support farmers both in Vietnam and other similar settings in the world.

Farmers in rural areas participated in this study reported low QOL. Saarni et al (2014) found that when comparing QOL between farmers and entrepreneurs, farmers scored significantly lower than entrepreneurs even when social economic factors were controlled [16]. Thus, our study provides additional support for the low QOL of farmers in rural areas and infers the rural - urban discrepancy in QOL. However, the QOL level reported in this study was significantly lower than some previous studies on Vietnamese people using WHOQOL-BREF, such as elderly in rural areas $[17,18,19]$. The main reason for this discrepancy might lie in the fact that our sample consisted of farmers only. Agriculture is no longer the desired occupation of rural people, especially if it relies on traditional farming 
methods (see our discussion on education below). Ho (2008) also reported a tendency of job shifting and urban migration in Vietnamese farmers [20].

The highest QOL domain score found in the psychological health domain reflects more positive feelings about life, good cognitive abilities and high self-esteem in farmers. Environmental health domain has the lowest score, implying less satisfaction with the current living conditions (safety, finance, environment) and the ability to access transport services and information. Previous studies have found that rural population tended to have less access to basic services than urban populations [10, 11]. This problem affects subjective QOL, as rural Americans had lower satisfaction with institutional services than urban American [10].

Education has a consistent effect on farmers' QOL: farmers with higher education tend to feel more satisfied with all aspects of life, especially physical health, social relationship and environmental health. This is in line with previous results [21, 22, 18]. Qualitative studies using focus group also found that in Asia, education is seen as the determinant of present and future of QOL [11]. Asian parents believed that investing in education can improve the QOL of their children; not to mention that many parents already feel their QOL has improved because their children are receiving a better education. Rural Asians also believe that future generations should find other jobs apart from farming because of its declining economic viability [11]. This might partly explain the low QOL of farmers in this study in the context of improved standard of living of farmers in rural areas in Vietnam over the last decades.

Both overall QOL score and domain scores were higher in male farmers than female farmers. The result is consistent with general differences found in previous findings in other Vietnamese samples using WHOQOL, such as rural people with hypertension [18], HIV/AIDS patients [23], and rural elderly [24, 25].

In this study, we considered the effect of family size through two factors: the number of family members and the number of working family members. The number of working family members predicted overall QOL and all 4 domains. When a family has more than 3 employed members, the QOL of individual member decreases. However, the number of family members did not predict QOL and its domains, although a reduction in QOL mean scores were observed when a family had more than 4 members. These two results should be considered together. A family with 4 members or less is usually a nuclear family; while a family with more than 3 employed members is most likely to be a multi-generation family (working grandparents living with working parents and grandchildren) or an adultdominated family (parents living with grown-up children or nuclear family living with aunts/uncles). Generation gap usually creates conflict in the family, as such living in a multi-generation family might reduce the QOL of its adult members. In addition, in Vietnamese culture, grown-up siblings are encouraged to live independently when they have their own family, as reflected through the Vietnamese idiom: "anh em kiến giả nhất phận" (married brothers live separate lives). As such, the co-living of grown-up siblings in a family might lead to conflict, reducing the QOL of individual family members.

QOL, living standard and income-expense balance have a complicated relationship. Farmers' QOL was highest among farmers with average living standard; it decreased when their living standard increased; yet those with the lowest living standard remain to have lowest QOL. While income-expense balance created a variation in QOL score, it did not predict QOL or its domains. In other words, living standard is a more powerful predictor of farmers' QOL than income-expense balance (i.e. monetary saving). Farmers with lower living standard and no saving had the lowest QOL. Having some saving might slightly increase their QOL, but if their living standard is much higher other people, they encounter more dissatisfaction with physical health, social relationship and environmental health. This 
is reflected in the higher mean score across all domains of QOL in farmers with average standard of living as compared to farmers with above-average standard of living.

However, when all variables were taken into account in the regression model, the effect of gender, age, marital status, number of family members and income-expense balance became insignificant. In other words, education, marital status, living standard and number of employed family members influenced farmers' QOL over and above other factors. Policies should target these socio-economic factors to help boost the QOL of farmers in rural areas in Vietnam.

This study has some limitations. This is a cross-sectional study, thus limiting its ability to infer causality between QOL and other factors. Secondly, while we use random selection, the sample cannot be representative of farmers in Vietnam, as our limited capacity restricts our ability to collect data in more regions and provinces or gathering a bigger sample. Future studies should examine longitudinal design and other sampling methods to address these problems.

\section{Conclusion}

This study examined QOL of farmers in rural areas in Vietnam and found low QOL across all domains. Various socio-economic factors contributed to differences in QOL among farmers; however, only 3 factors were strong enough to predict QOL of farmers in rural areas: education, living standard and number of working family members. While the association between education and QOL confirmed previous findings, the links between QOL and living standard and number of working family members reflect unique characteristics of farmers in rural Vietnam, especially their detachment to agriculture and the increasingly individualistic lifestyle in the rural areas. Rural policies should consider these factors in designing interventions to improve farmers' QOL.

\section{References}

1. A/RES/70/1 - Transforming our world: the 2030 Agenda for Sustainable Development (United Nations, 2015)

2. L. Chase, R. Boumans, S. Morse, Com. Dev. 41, 385 (2010)

3. A. Marsella, L. Levi, S. Ekblad, Appl. Prev. Psych 6, 55 (1997)

4. L. Chase, B. Amsden, R. Phillips, Handbook on tourism and quality of life research: Enhancing the Lives of Tourists and Residents of Host Communities (Springer Publishing Company, New York, 2012)

5. R. Costanza, B. Fisher, S. Ali, C. Beer, L. Bond et al., Ecol. Econ. 61, 267 (2007)

6. M. Sirgy, D. Rahtz, M. Cicic, R. Underwood, Soc. Ind. Res. 49, 279 (2000)

7. L. Borja, Handbook of Research Methods and Applications in Happiness and Quality of Life (Edward Elgar Publishing, 2016)

8. P. De Muro, 3rd WYE City Project 24 (2010)

9. The WHOQOL Group, Int. J. Ment. Heal. 23, 24 (1994)

10. D. Dillman, K. Tremblay, ANNALS America Academy of Political and Social Science 429, 115 (1977)

11. D. Bloom, P. Craig, P. Malaney, The Quality of life in Rural Asia (Oxford University Press, Hong Kong, 2001)

12. G. Smith, G. Strachan, D. Gibbon, Int. J. Sustain. Dev. World 25, 592 (2018) 
13. C. Leck, N. Evans, D. Upton. J. Rur. Stud 34, 313 (2014)

14. T. Dax, W. Strahl, J. Kirwan, Eur Urb. Reg. Stu 23, 56 (2016)

15. General Statistics Office of Vietnam. Selected key indicators the Vietnam population and housing census on 1st April 2019 (2019)

16. S. Saarni, E. Saarni, H. Saarni, Occup. Env. Med. 65, 98 (2008)

17. N. Van, N. Van, N. Duc, N. Van, N. The, J. Prev. Med. Hyg. 58, 63 (2017)

18. N. Ha, D. Hoa, L. Ninh, V. Khanal, R. Moorin, BMC Pub. Heal. 14, 833 (2014)

19. N. Vo, T. Vo, S. Watanapongvanich, N. Witvorapong, Soc. Indic. Res. 142, 1285 (2019)

20. H. Viet, $3^{\text {rd }}$ International Conference on Vietnamese Studies Proceedings (2008)

21. A. Gholami, L. Jahromi, E. Zarei, A. Dehghan, Int. J. Prev. Med. 4, 809 (2013)

22. N. Ng, M. Hakimi, P. Byass, S. Wilopo, S. Wall, Glob. Heal. Act. 3, 2125 (2010)

23. B. Tran, A. Ohinmaa, L. Nguyen, P. Oosterhoff, P. Vu, T. Vu, M. Larsson, AIDS Care 24, 1187 (2012)

24. H. Minh, P. Byass, N. Chuc, S. Wall, Glob. Heal. Act. 3, 2124 (2010)

25. L. Hoi, N. Chuc, L. Lindholm, BMC Pub. Heal. 10, 549 (2010) 